\title{
Roles for Socially-Engaged Philosophy of Science in Environmental Policy
}

\author{
Kevin C. Elliott
}

\section{Lyman Briggs College, Department of Fisheries and Wildlife, and Department of Philosophy, Michigan State University}

\section{Introduction}

The philosophy of science has much to contribute to the formulation of public policy. Contemporary policy making draws heavily on scientific information, whether it be about the safety and effectiveness of medical treatments, the pros and cons of different economic policies, the severity of environmental problems, or the best strategies for alleviating inequality and other social problems. When science becomes relevant to public policy, however, it often becomes highly politicized, and figures on opposing sides of the political spectrum draw on opposing bodies of scientific information to support their preferred conclusions. ${ }^{1}$ One has only to look at contemporary debates over climate change, vaccines, and genetically modified foods to see how these debates over science can complicate policy making. ${ }^{2}$

When science becomes embroiled in policy debates, questions arise about who to trust and how to evaluate the quality of the available scientific evidence. For example, historians have identified a number of cases where special interest groups sought to influence policy by amplifying highly questionable scientific claims about public-health and environmental issues like tobacco smoking, climate change, and industrial pollution. ${ }^{3}$ Determining how best to respond to these efforts is a very important question that cuts across multiple disciplines. One does not want to be too quick to stifle dissenting views, because dissent can sometimes play a valuable role in correcting misconceptions and promoting scientific progress. ${ }^{4}$ Nevertheless, there are clearly cases where special-interest groups have hampered good policy making by manipulating science in unacceptable ways. ${ }^{5}$ Moreover, even when no one is deliberately 
attempting to manipulate or misrepresent research, the inherent uncertainty involved in most environmental research can make it very difficult to decide how to handle disagreements between different scientists and policy makers.

Philosophers of science have recently performed a good deal of work that can help promote better policy making in the face of these challenges. In fact, the philosophy of science has recently seen a proliferation of scholarly societies, books, journal articles, and special issues dedicated to public policy and more general questions about how the field can be socially engaged. ${ }^{6}$ This chapter focuses specifically on issues related to environmental research and policy as an illustration of three ways in which the philosophy of science can benefit policy making. First, it can help clarify the roles that values play in policy-relevant science. Second, it can help guide decision makers in evaluating and addressing scientific dissent, especially in response to controversial policy issues. Third, it can help guide thoughtful policy responses to scientific uncertainty.

\section{Science and Values}

One of the important ways in which the philosophy of science can contribute to better policy making is by clarifying the roles that values play in policy-relevant scientific research. It has been common in policy contexts to draw a relatively sharp distinction between facts and values, with the idea that science supplies policy makers with relatively straightforward facts, and the preferences of the public or their government representatives supply values. An example of this distinction in the context of environmental research is the distinction employed by the U.S. government between risk assessment and risk management. ${ }^{7}$ Traditionally, risk assessment has been regarded as a fairly straightforward scientific process of determining the probability 
that particular hazards will cause specific health effects at the levels to which people are exposed. In contrast, risk management has been regarded as a value-laden process of deciding whether or not those health effects are tolerable and what to do about them, given the range of social costs and benefits associated with them. ${ }^{8}$

This effort to keep policy-relevant science free of values has turned out to be more difficult than it initially appears. One can begin to appreciate the difficulties by looking at the process of risk assessment for toxic chemicals. It turns out that in order to produce a risk assessment, scientists have to make a host of judgments that are not settled by the available evidence. ${ }^{9}$ For example, they typically test toxic chemicals on animals like rats, and they have to make choices about how to extrapolate from the effects on the rats to the effects that are likely to occur in humans. They also typically test the chemicals at relatively high doses, which means they have to estimate how the effects will change at lower doses. They also have to estimate how the effects will vary on pregnant women or children or other particularly sensitive individuals. In addition, risk assessors often encounter some studies that appear to show that a chemical is toxic at particular dose levels and others that appear to show that it is not toxic at those levels. In these cases, they have to make additional judgments about which studies to trust. All these judgments are "value-laden," in the sense that they are not settled by the available evidence but can have a major impact on the outcome of a risk assessment. Thus, even if scientists do not intend to support some social values over others when they make these judgments, they are ultimately forced to do so. ${ }^{10}$

The philosophy of science can make a valuable contribution to public policy by clarifying the range of "decision points" where value-laden judgments arise in policy-relevant science. I have previously argued that there are at least five decision points that are important to consider: 
(1) choices about research topics; (2) decisions about what questions to ask regarding those topics; (3) choices about the aims of inquiry, which determine what count as adequate answers to the questions being asked; (4) decisions about standards of evidence for drawing conclusions; and (5) choices about how to describe and frame scientific findings. ${ }^{11}$

Philosophers have highlighted a number of ways in which environmental research is affected by values at these decision points. For example, in accordance with the second decision point mentioned above, Hugh Lacey has pointed out that risk assessments of emerging technologies tend to focus on examining some questions about their effects (e.g., potential human health effects or environmental effects) while ignoring other questions (e.g., their social or economic effects). ${ }^{12}$ As a result, the risk-assessment process can look very objective while still being significantly value-laden. In accordance with the fourth decision point, a number of philosophers have emphasized that judges and regulators are forced to make ethically significant choices about how much evidence and what kinds of evidence to demand before concluding that potential environmental threats are likely to occur. ${ }^{13}$ In accordance with the fifth decision point, I have argued that even the terms and categories used for describing environmental issues can affect public perceptions of them in ways that are socially significant. ${ }^{14}$ Debates about terminology have occurred in a wide range of environmental contexts, including climate change, invasive species, endocrine disruption, genetic modification, climate geoengineering, and many others. ${ }^{15}$

Once these sorts of value judgments have been clarified, it becomes possible to scrutinize and critique them. In some cases, it might be desirable for scientists to try to avoid making the value judgments so that they could be handled by policy makers instead. ${ }^{16}$ In other cases, it might be sufficient for the scientists to clarify the value judgments that they made so that others 
could consider whether or not they agree with them ${ }^{17}$ In still other cases, scientists might be able to collaborate with policy makers and other stakeholders to decide how to make important judgments. ${ }^{18}$ However one chooses to respond to these value judgments, the goal is to develop a better understanding of how they influence the science that informs policy decisions.

\section{Scientific Dissent}

A second way in which the philosophy of science can contribute to policy making is by helping to navigate scientific dissent. A pervasive feature of policy-relevant science, especially environmental science, is the presence of disagreement. In some cases, such as climate-change denial, it is fairly clear that one side of the debate is inappropriately raising bogus objections or misrepresenting the available evidence. ${ }^{19}$ In many cases, however, there are legitimate questions about how to interpret the available scientific evidence. For example, the scientific community has been debating the human health effects of bisphenol A (BPA) for more than a decade. ${ }^{20} \mathrm{BPA}$ is used in a wide variety of products, including can liners and cash-register receipts, but it appears to act as an endocrine disruptor, which means that it can potentially cause health problems by interfering with the endocrine system. While many academic studies have suggested that BPA has the potential to harm human health at the levels to which people are currently exposed, important studies of BPA performed by the chemical industry have not indicated that it is harmful. ${ }^{21}$ As a result, major regulatory agencies in the United States and the European Union have been slow to regulate it. $^{22}$

In response to these sorts of cases, it might be tempting to try to squelch scientific dissent and strive for consensus. Nevertheless, philosophers of science have pointed out that there are significant dangers to doing so. ${ }^{23}$ As we have seen, policy-relevant science is invariably value- 
laden, and it is often difficult to distinguish value judgments that are reasonable from those that are problematic. In response to this difficulty, a number of philosophers have argued that scientific objectivity is most likely to be secured by fostering critical interaction between people with varying perspectives so that they can uncover implicit value judgments and subject them to adequate scrutiny. ${ }^{24}$ On this account, dissent is central to maintaining scientific objectivity. Moreover, Inma de Melo-Martin and Kristen Intemann have emphasized that dissent can promote scientific progress by ensuring that a wide range of research projects, explanations, and assumptions all receive adequate attention. ${ }^{25}$ They note that dissent can also strengthen consensus views by ensuring that they have been thoroughly examined, and this in turn can strengthen public trust in science.

Given that dissent can be problematic in some circumstances but beneficial in other contexts, philosophers of science have recently proposed a variety of criteria for distinguishing appropriate and inappropriate dissent. For example, Justin Biddle and Anna Leuschner have argued that dissent is problematic if the non-epistemic consequences of wrongly rejecting a scientific claim are significant, if the dissent violates established epistemic standards, if the dissent promotes public risks over producer risks, and if producer risks and public risks fall on different parties. ${ }^{26}$ This account makes it clear why dissent about climate change appears to be problematic. Wrongly rejecting climate change is likely to have dire consequences, and those who question the evidence for climate change appear to be depending on false and misleading arguments. Moreover, the major effects of climate change fall particularly heavily on the public, including groups that are already disadvantaged, while the costs of responding to climate change are particularly salient to corporations that produce or depend on energy from fossil fuels. 
Unfortunately, while Biddle and Leuschner's account of problematic dissent may be helpful in some cases, it does not appear to be fully adequate. Specifically, de Melo-Martin and Intemann have argued that it can be very difficult to determine whether the criteria proposed by Biddle and Leuschner have been met. ${ }^{27}$ For example, there is often room for disagreement about which epistemic standards are legitimate and how to interpret them. In addition, there are often a wide range of consequences associated with dissenting scientific views, which means that it can be difficult to decide whether producer risks are actually being prioritized over public risks. De Melo-Martin and Intemann argue that the difficulties faced by Biddle and Leuschner are typical of most efforts to develop criteria for distinguishing appropriate and inappropriate dissent; in the thick of scientific debate, it is difficult to apply the criteria successfully. ${ }^{28}$

Instead of depending on a set of criteria, de Melo-Martin and Intemann recommend shifting attention away from dissent and focusing instead on fostering scientific institutions that engender public trust. ${ }^{29}$ They argue that when the public has trust in scientific institutions, special-interest groups will find it much more difficult to wield dissent as an excuse for resisting well-supported scientific conclusions. By alleviating the problematic consequences of dissent, they suggest that it becomes less important to try to draw sharp distinctions between appropriate and inappropriate forms of dissent. De Melo-Martin and Intemann suggest a variety of strategies for promoting greater trust, including the development of better approaches for addressing conflicts of interest and preventing scientific misconduct. ${ }^{30}$

Another strategy for productively addressing scientific dissent is to formulate public policies in strategic ways that do not depend too heavily on detailed scientific information. Science policy scholars have pointed out that in polarized political contexts, those on opposite sides of political debates are likely to wield science as a strategic tool for strengthening their 
positions. ${ }^{31}$ As a result, it is very difficult to resolve political disputes using science; when science is brought into these disputes, it is likely to become sucked into the political debates. Therefore, it is often most productive to develop creative regulatory and policy strategies that can alleviate political debates without depending too heavily on detailed scientific information. ${ }^{32}$

\section{Responding to Uncertainty}

A third way in which the philosophy of science, and the field of philosophy more broadly, can contribute to thoughtful policy making is by providing guidance for responding to scientific uncertainty. Environmental policy making in particular is plagued by uncertainty, and philosophers have made important contributions to thinking about how to respond to this problem. Three concepts in particular have played an important role in recent philosophical work on this issue: inductive risk, the precautionary principle, and argumentative analysis.

As discussed earlier in this chapter, one of the important value judgments that scientists and policy makers need to make when addressing uncertainty in policy-relevant research is to decide what standards of evidence to demand before drawing conclusions. ${ }^{33}$ This value judgment arises because scientists always face inductive risk, which is the possibility that their inferences will end up being incorrect. ${ }^{34}$ Philosophers of science have recently spilled a great deal of ink reflecting on how scientists and policy makers can respond to inductive risk in a responsible fashion. ${ }^{35}$ Some have argued that scientists should strive to hedge their conclusions so carefully that their claims become relatively certain and free of inductive risk. ${ }^{36}$ Others have argued that this effort to avoid uncertainty is unrealistic, and scientists should instead weigh the costs and benefits of drawing false-positive or false-negative errors when setting standards of evidence. ${ }^{37}$ For example, if the costs of drawing a false-positive error were particularly low and the costs of 
drawing a false-negative error were especially high in a particular context, it might make sense for scientists to lower their standards of evidence so that they would be less likely to make a false-negative error.

Deciding how to perform this weighing process in a responsible manner raises a number of additional questions. Some have argued that scientists should, if at all possible, merely express the probability that particular conclusions are true and then let policy makers decide whether or not to accept those conclusions. ${ }^{38}$ Others have argued that scientists should choose a fixed standard of evidence so that the public is less likely to become confused about the amount of confidence that scientists have in their conclusions. ${ }^{39}$ Still others argue that scientists can adjust their standards of evidence in different contexts, depending on the social consequences of making particular sorts of mistakes, as long as they are sufficiently transparent about the standards of evidence that they are choosing. ${ }^{40}$ Another approach is to promote as much engagement as possible between scientists, policy makers, and other stakeholders so that they can decide how to respond to inductive risk in a collaborative fashion. ${ }^{41}$

Another way in which philosophers have assisted in addressing uncertainty in policyrelevant science — and specifically uncertainty about environmental threats — is by clarifying the concept of the precautionary principle. The precautionary principle calls on decision makers to address uncertainty by taking precautionary measures to address serious or irreversible threats even when the scientific information about those threats is limited. ${ }^{42}$ The precautionary principle has been the subject of intense debate, with some commentators arguing that it is a matter of common sense and others arguing that it is a paralyzing principle that is impossible to follow. ${ }^{43}$ Philosophers have clarified that at least some of this confusion can be traced to ambiguity about at least three aspects of the principle: (1) the types of threats that should trigger the principle; (2) 
the amount of scientific information required in order to justify taking precautionary measures; and (3) the types of precautionary actions that should be taken. ${ }^{44}$ Critics of the principle tend to interpret it so that it requires dramatic steps to prevent potential threats, even if there is very little evidence that they will occur, while proponents of the principle tend to interpret it in much more reasonable ways.

The precautionary principle is also sometimes used in an even broader range of ways, referring to practices like setting goals for reducing the use of hazardous substances, shifting the burden of proof onto polluters to show that their activities are safe, carefully examining alternatives to potentially hazardous activities, and incorporating public participation in assessing and managing risks. ${ }^{45}$ Clarifying these different interpretations of the precautionary principle does not resolve all disputes about it; there are still important ethical disagreements about whether particular interpretations of it provide good guidance for handling uncertainty. Nevertheless, conceptual clarification can at least help prevent people from talking past each other and instead promote fruitful discussion of these ethical disagreements.

Finally, philosophers have also been contributing to better policy making under uncertainty by employing what Sven Ove Hansson and Gertrude Hirsch Hadorn have called "argumentative analysis." 46 Hansson and Hirsch Hadorn argue that policy making has been dominated by formal, technical methods such as risk analysis and cost-benefit analysis, but that these methods are problematic in cases where there is so much uncertainty that it is difficult to assign precise probabilities and consequences to the actions under consideration. ${ }^{47}$ They argue that argumentative analysis can be employed by philosophers to accomplish a number of tasks: to better understand the uncertainties involved in decisions, to prioritize among uncertain dangers, to determine how decisions should be framed, to clarify how 
different decisions on interconnected subject-matter relate to each other, to choose a suitable time frame for decision-making, to analyse [sic] the ethical aspects of a decision, to systematically choose among different decision options, and not least to improve our communication with other decision-makers in order to co-ordinate our decisions. $^{48}$

Argumentative analysis has much to offer environmental policy making, where uncertainty is ubiquitous. Consider climate geoengineering, which consists of the deliberate manipulation of earth systems, especially in response to climate change. ${ }^{49}$ Some scientists have suggested that we could cool the planet using techniques like shooting sulfur aerosols into the atmosphere or stimulating the growth of ocean plankton in order to absorb carbon dioxide. ${ }^{50} \mathrm{In}$ the face of massive uncertainty about the consequences of choosing whether or not to employ these techniques, formal methods for decision analysis face significant challenges. Faced with these difficulties, philosophers have explored the strengths and weaknesses of different ways of framing decisions about geoengineering, such as by regarding it as a form of insurance or as a technical fix. ${ }^{51}$ They have also explored ethical questions, such as whether it would be problematic to alter nature in such a significant way, or whether geoengineering poses a "moral hazard," or whether it can be justified as the "lesser of two evils." ${ }^{, 2}$ Finally, they have investigated procedural questions about what form of public consent, if any, would be needed in order to justify engaging in climate geoengineering. ${ }^{53}$ Cases like this one illustrate that argumentative analysis need not be limited to philosophers of science. Ethicists, political philosophers, and decision theorists also have much to contribute, but the philosophy of science has an important role to play alongside these other specialties. 


\section{Conclusion}

This chapter has explored three ways in which the philosophy of science can contribute to better policy making, especially with respect to environmental issues. First, the philosophy of science can help to clarify the roles that values play in policy-relevant science. Second, it can help guide policy makers in evaluating and responding to dissenting scientific views. Third, it can help guide decision making in response to scientific uncertainty.

Of course, philosophers of science who want to contribute to public policy still have a great deal of work to do. Even though scholars now have a more sophisticated understanding of the roles that values play in policy-relevant science, there is still a great deal of confusion about the conditions under which particular influences of values are appropriate and the best ways to achieve transparency about those value influences. Similar confusion surrounds the conditions under which scientific dissent is appropriate and the best ways of responding to dissent. And even though philosophers have helped to clarify a number of issues involved in formulating policy under scientific uncertainty, it remains an extremely difficult topic that merits much more work.

As philosophers continue to address these questions, they also need to reflect on the best ways to make their work useful and available to the policy community. This may require collaborating on research projects with scholars from outside philosophy, publishing in a range of journals and other venues that engage more diverse audiences, and altering professional incentives so that philosophers are rewarded for performing these activities. By being creative both about the nature of their work and how they share it with broader communities, philosophers of science will hopefully achieve their goal of performing effective, socially engaged scholarship. 
${ }^{1}$ Daniel Sarewitz, "How Science Makes Environmental Controversies Worse," Environmental Science \& Policy 7 (2007): 385-403.

${ }^{2}$ David Harker, Creating Scientific Controversies: Uncertainty and Bias in Science and Society (Cambridge: Cambridge University Press, 2015); Naomi Oreskes and Erik Conway, Merchants of Doubt: How a Handful of Scientists Obscured the Truth on Issues from Tobacco Smoke to Global Warming (New York: Bloomsbury, 2010).

${ }^{3}$ Kevin Elliott (2016b), "Environment," in Miseducation, ed. A.J. Angulo (Baltimore: Johns Hopkins University Press, 2016), 96-119; Gerald Markowitz and David Rosner, Deceit and Denial: The Deadly Politics of Environmental Pollution (Berkeley: University of California Press, 2002); Oreskes and Conway, Merchants of Doubt.

${ }^{4}$ Inma de Melo-Martin and Kristen Intemann, The Fight Against Doubt (New York: Oxford University Press, 2018).

${ }^{5}$ Bennett Holman and Kevin Elliott, "The Promise and Perils of Industry-Funded Science," Philosophy Compass (forthcoming); Markowitz and Rosner, Deceit and Denial; Oreskes and Conway, Merchants of Doubt.

${ }^{6}$ Francis Cartieri and Angela Potochnik, "Toward Philosophy of Science's Social Engagement," Erkenntnis 79 (2013): 1-16; Heather Douglas, Science, Policy, and the Value-Free Ideal (Pittsburgh: University of Pittsburgh Press, 2009); Kevin Elliott and Ted Richards, editors, Exploring Inductive Risk: Case Studies of Values in Science (New York: Oxford University Press, 2017); Kevin Elliott and Ted Richards, "Introduction: The Responsible Use of Science in Societal Decision Making_Part 1," Public Affairs Quarterly 31 (2017): 157-163; de Melo-Martin and Intemann, The Fight Against Doubt; Katie Plaisance and Carla Fehr, "Socially Relevant Philosophy of Science: An Introduction," Synthese 177 (2010): 301-316. In addition to these books and journal issues, it is noteworthy that several scholarly societies or organizations have recently formed, including JCSEPHS (the Joint Caucus for Socially Engaged Philosophy and History of Science) and SRPoiSE (the Consortium for Socially Relevant Philosophy of/in Science and Engineering).

${ }^{7}$ See, for example, National Research Council, Risk Assessment in the Federal Government: Managing the Process (Washington, DC: National Academies Press, 1983); Ellen Silbergeld, "Risk Assessment and Risk Management: An Uneasy Divorce," in Acceptable Evidence: Science and Values in Risk Management, ed. Deborah Mayo and Rachelle Hollander (New York: Oxford University Press, 1991), 99-114.

${ }^{8}$ National Research Council, Risk Assessment.

${ }^{9}$ Silbergeld, "Risk Assessment and Risk Management."

${ }^{10}$ Kevin Elliott, A Tapestry of Values: An Introduction to Values in Science (New York: Oxford University Press, 2017).

${ }^{11}$ Elliott, Tapestry of Values.

${ }^{12}$ Hugh Lacey, "The Safety of Using Genetically Engineered Organisms: Empirical Evidence and Value Judgments," Public Affairs Quarterly 31 (2017): 259-279.

${ }^{13}$ Carl Cranor, Regulating Toxic Substances: A Philosophy of Science and the Law (New York: Oxford University Press, 1993); Douglas, Science, Policy, and the Value-Free Ideal; Kevin Elliott, Is a Little Pollution Good for You? Incorporating Societal Values in Environmental Research (New York: Oxford University Press, 2011); Kristin Shrader-Frechette, The Ethics of Scientific Research (Lanham, MD: Rowman and Littlefield, 1994).

${ }^{14}$ Kevin Elliott, "The Ethical Significance of Language in the Environmental Sciences," Ethics, Place \& Environment 12 (2009): 157-173; Kevin Elliott, "Climate Geoengineering," in The Argumentative Turn in Policy Making: Reasoning about Uncertainty, ed. Sven Ove Hansson and Gertrude Hirsch Hadorn (Cham: Springer), 305324.

${ }^{15}$ Elliott, Tapestry of Values; Brendon Larson, Metaphors for Environmental Sustainability: Redefining Our Relationships with Nature (New Haven, CT: Yale University Press, 2011).

${ }^{16}$ Gregor Betz, "Why the Argument from Inductive Risk Doesn't Justify Incorporating Non-Epistemic Values in Scientific Reasoning," Current Controversies in Values and Science, ed. Kevin Elliott and Daniel Steel (New York: Routledge), 94-110; Robert Hudson, "Why We Should Not Reject the Value-Free Ideal of Science," Perspectives on Science 24 (2016): 167-191.

${ }^{17}$ Kevin Elliott and David Resnik, "Science, Policy, and the Transparency of Values," Environmental Health Perspectives 122 (2014): 647-650; Roger Stanev, "Inductive Risk and Values in Composite Outcome Measures," in Exploring Inductive Risk: Case Studies of Values in Science, eds. Kevin Elliott and Ted Richards (New York: Oxford University Press, 2017), 171-191.

${ }^{18}$ Kevin Elliott and Ted Richards, "Exploring Inductive Risk: Future Questions," in Exploring Inductive Risk: Case Studies of Values in Science, eds. Kevin Elliott and Ted Richards (New York: Oxford University Press, 2017), 261277; Joyce Havstad and Matthew Brown, "Inductive Risk, Deferred Decisions, and Climate Science Advising," 
Exploring Inductive Risk: Case Studies in Values and Science, eds. Kevin Elliott and Ted Richards (New York: Oxford University Press, 2017), 101-123.

${ }^{19}$ Oreskes and Conway, Merchants of Doubt.

${ }^{20}$ Elliott and Resnik, "Science, Policy"; David Resnik and Kevin Elliott, "Bisphenol A and Risk Management Ethics," Bioethics 29 (2015): 182-189; Laura Vandenberg and Gail Prins, "Clarity in the Face of Confusion: New Studies Tip the Scales on Bisphenol A (BPA)," Andrology 4 (2016): 561-564; Frederick vom Saal and Charles Hughes, "An Extensive New Literature Concerning Low-Dose Effects of Bisphenol A Shows the Need for a New Risk Assessment," Environmental Health Perspectives 113 (2005): 926-933.

${ }^{21}$ Vandenberg and Prins, "Clarity."

${ }^{22}$ Resnik and Elliott, "Bisphenol A."

${ }^{23}$ Kristen Intemann, "Who Needs Consensus Anyway? Addressing Manufactured Doubt and Increasing Public Trust in Climate Science," Public Affairs Quarterly 31 (2017): 189-208.

${ }^{24}$ Sandra Harding, Objectivity and Diversity: Another Logic of Scientific Research (Chicago: University of Chicago Press, 2015); Helen Longino, The Fate of Knowledge (Princeton: Princeton University Press, 2002).

${ }^{25}$ de Melo-Martin and Intemann, Fight Against Doubt.

${ }^{26}$ Justin Biddle and Anna Leuschner, "Climate Skepticism and the Manufacture of Doubt: Can Dissent in Science

Be Epistemically Detrimental?” European Journal for Philosophy of Science 5 (2015): 261-278.

${ }^{27}$ de Melo-Martin and Intemann, Fight Against Doubt.

${ }^{28}$ de Melo-Martin and Intemann, Fight Against Doubt.

${ }^{29}$ de Melo-Martin and Intemann, Fight Against Doubt.

${ }^{30}$ de Melo-Martin and Intemann, Fight Against Doubt.

${ }^{31}$ Roger Pielke, Jr., The Honest Broker: Making Sense of Science in Policy and Politics (Cambridge: University of Cambridge Press, 2007); Daniel Sarewitz, "How Science."

${ }^{32}$ Elliott, "Environment"; Sarewitz, "How Science."

${ }^{33}$ Douglas, Science, Policy, and the Value-Free Ideal; Elliott, Is a Little Pollution.

${ }^{34}$ Elliott and Richards, Exploring Inductive Risk.

${ }^{35}$ Betz, "Why the Argument"; Douglas, Science, Policy, and the Value-Free Ideal; Elliott and Richards, "Exploring Inductive Risk: Future Questions"; Stephen John, "Inductive Risk and the Contexts of Communication." Synthese 192 (2015): 79-96.

${ }^{36}$ Betz, "Why the Argument."

${ }^{37}$ Douglas, Science, Policy, and the Value-Free Ideal; David Frank, "Making Uncertainties Explicit: The Jeffreyan Value-Free Ideal and Its Limits," in Exploring Inductive Risk: Case Studies of Values in Science, eds. Kevin Elliott and Ted Richards (New York: Oxford University Press, 2017), 79-100; Havstad and Brown, "Inductive Risk."

${ }^{38}$ Betz, "Why the Argument"; Hudson, "Why We Should Not."

${ }^{39}$ John, "Inductive Risk."

${ }^{40}$ Heather Douglas, "The Role of Values in Expert Reasoning," Public Affairs Quarterly 22 (2008): 1-18; Elliott and Resnik, "Science, Policy."

${ }^{41}$ Heather Douglas, "Inserting the Public into Science," in Democratization of Expertise? Exploring Novel Forms of Scientific Advice in Political Decision-Making, eds. Sabine Maasen and Peter Weingart (New York: Springer, 2005), 153-169; Elliott, Is a Little Pollution; Havstad and Brown, "Inductive Risk."

${ }^{42}$ Carolyn Raffensperger and Joel Tickner, "Introduction: To Foresee and To Forestall," in Protecting Public Health and the Environment: Implementing the Precautionary Principle, eds. Carolyn Raffensperger and Joel Tickner (Washington, D.C.: Island Press, 1999).

${ }^{43}$ Kevin Elliott, "Geoengineering and the Precautionary Principle," International Journal of Applied Philosophy 24 (2010): 237-253.

${ }^{44}$ Neil Manson, "Formulating the Precautionary Principle," Environmental Ethics 24 (2002): 263-274; Per Sandin, "Dimensions of the Precautionary Principle," Human and Ecological Risk Assessment 5 (1999): 889-907.

${ }^{45}$ Elliott, "Geoengineering and the Precautionary Principle"; Joel Tickner, "A Map Toward Precautionary Decision Making," in Protecting Public Health and the Environment: Implementing the Precautionary Principle, eds.

Carolyn Raffensperger and Joel Tickner (Washington, D.C.: Island Press, 1999), 162-186.

${ }^{46}$ Sven Ove Hansson and Gertrude Hirsch Hadorn, editors, The Argumentative Turn in Policy Analysis: Reasoning about Uncertainty (Switzerland: Springer, 2016).

${ }^{47}$ Sven Ove Hansson and Gertrude Hirsch Hadorn, "Introducing the Argumentative Turn in Policy Analysis," in The Argumentative Turn in Policy Analysis: Reasoning about Uncertainty, eds. Sven Ove Hansson and Gertrude Hirsch Hadorn (Cham: Springer, 2016), 11-35.

${ }^{48}$ Hansson and Hirsch Hadorn, "Introducing the Argumentative Turn," p. 31. 
${ }^{49}$ Elliott, "Climate Geoengineering."

${ }^{50}$ Royal Society (2009), Geoengineering the Climate: Science, Governance, and Uncertainty. Royal Society Policy Document 10/09. https://royalsociety.org/ /media/Royal_Society_Content/policy/publications/2009/8693.pdf

${ }^{51}$ Dane Scott, "Insurance Policy or Technological Fix? The Ethical Implications of Framing Solar Radiation Management," in Engineering the Climate: The Ethics of Solar Radiation Management, ed. Christopher Preston (Lanham: Lexington Books, 2012), 151-169.

${ }^{52}$ Stephen Gardiner, "Is 'Arming the Future' with Geoengineering Really the Lesser Evil? Some Doubts about the Ethics of Intentionally Manipulating the Climate System," in Climate Ethics: Essential Readings, eds. Stephen Gardiner, Simon Caney, Dale Jamieson, and Henry Shue (New York: Oxford University Press, 2010), 284-312; Ben Hale "The World That Would Have Been: Moral Hazard Arguments against Geoengineering," Engineering the Climate: The Ethics of Solar Radiation Management, ed. Christopher Preston (Lanham: Lexington Books, 2012), 113-131.

${ }^{53}$ Kyle Powys Whyte, "Indigenous People, Solar Radiation Management, and Consent," Engineering the Climate: The Ethics of Solar Radiation Management, ed. Christopher Preston (Lanham: Lexington Books, 2012), 65-76. 